\title{
Análise de Ensaios Não-Destrutivos para Inspeção de Tubos de Trocadores de Calor do Tipo Casco \& Tubos: Campo Remoto (RFT) versus Sistema de Inspeção Rotativa Interna (IRIS)
}

\author{
Rafael Nardon Ferraresi ${ }^{1}$, Vitor Calasense de Campos $^{1}$, Gabriel Cicelini ${ }^{1}$, Weslley Carlos Dias da Silva ${ }^{2}$, Ruham Pablo Reis ${ }^{1}$ (D), \\ Valtair Antônio Ferraresi ${ }^{1}$ \\ ${ }^{1}$ Universidade Federal de Uberlândia - UFU, Uberlândia, MG, Brasil. \\ ${ }^{2}$ Centro de Pesquisas, Desenvolvimento e Inovação Leopoldo Américo Miguez de Mello - CENPES, Petrobras, Rio de Janeiro, RJ, Brasil.
}

Como citar: Ferraresi RN, Campos VC, Cicelini G, Silva WCD, Reis RP, Ferraresi VA. Análise de ensaios não-destrutivos para inspeção de tubos de trocadores de calor do tipo casco \& tubos: Campo Remoto (RFT) versus Sistema de Inspeção Rotativa Interna (IRIS). Soldagem \& Inspeção. 2021;26:e2613. https://doi.org/10.1590/0104-9224/SI26.13

\begin{abstract}
Resumo: Trocadores de calor do tipo casco e tubos são amplamente utilizados em diversos setores, incluindo na indústria de óleo e gás, onde sofrem corrosão sob variadas formas. Atualmente, a inspeção não-destrutiva desses tubos é comumente realizada por Sistema de Inspeção Rotativa Interna (IRIS), técnica de ultrassom reconhecida pela identificação visual das descontinuidades, mas também pelo alto custo operacional, inclusive no quesito baixa velocidade de ensaio. Se contrapondo ao IRIS, tem-se a técnica de Campo Remoto (RFT), teste não-destrutivo baseado em campos magnéticos para indicação de descontinuidades, que vem ganhando espaço pelo menor custo operacional, principalmente relacionado à velocidade de ensaio bastante superior à do IRIS. Diante da forte dependência de interpretação por parte do inspetor e visando uma melhor compreensão de suas variáveis e efeitos, bem como de seu desempenho frente ao ensaio IRIS em diferentes tipos de descontinuidades, este trabalho visa a contribuir para o entendimento da técnica RFT e da influência de seus parâmetros de operação, especificamente frequência de excitação e velocidade de tracionamento da sonda, e efeito da placa de suporte na leitura e interpretação dos resultados. Para tanto, foram realizados ensaios RFT em tubos de aço carbono utilizados em trocadores do tipo casco e tubos com diversas frequências para os canais absoluto e diferencial da sonda. Uma melhor adequação foi verificada quando os canais são submetidos a diferentes frequências, sendo que os valores mais adequados devem ser determinados no momento do ensaio, considerando variações nos tubos, principalmente a permeabilidade magnética. Valores de velocidade de tracionamento da sonda RFT superiores a $568 \mathrm{~mm} / \mathrm{s}$ dificultam a leitura das descontinuidades. Descontinuidades a menos de $115 \mathrm{~mm}$ de distância da placa de suporte não são detectadas pelos canais absoluto e diferencial do RFT, necessitando do canal MIX, que faz a subtração do sinal da placa. Frente ao IRIS, o ensaio RFT, apesar de não permitir intrinsicamente o dimensionamento das descontinuidades, se mostrou bem mais rápido em termos de execução da varredura e com capacidade de detecção similar.
\end{abstract}

Palavras-chave: IRIS; RFT; Campo Remoto; Inspeção não-destrutiva; Trocadores de calor.

\section{Analysis of Non-Destructive Tests for Inspection of Tubes from Shell-and-Tube Heat Exchangers: Remote Field (RFT) versus Internal Rotary Inspection System (IRIS)}

\begin{abstract}
Shell-and-tube heat exchangers are widely used in several sectors, including in the oil and gas industry, where they undergo corrosion in varied ways. Currently, the non-destructive inspection of such tubes is commonly performed by the Internal Rotating Inspection System (IRIS), an ultrasound technique recognized for the visual identification of discontinuities, but also for its high operational cost, including in terms of low testing speed. In contrast to IRIS, there is the Remote Field technique (RFT), a non-destructive test based on magnetic fields to indicate discontinuities, which is gaining momentum due to the lower operating cost, especially related to the test speed much higher than that performed by IRIS. Given the strong dependence on the interpretation on the part of the inspector and targeting at a better understanding of its variables and effects, as well as its performance against the IRIS test in different types of discontinuities, this work aims at contributing to the understanding of the RFT technique and the influence of its operating parameters, specifically the probe excitation frequency and traction speed, and effect of the support plate on the reading and interpretation of the results. For this purpose, RFT tests were carried out on carbon steel tubes used in
\end{abstract}

Recebido: 12 Abr., 2021. Aceito: 29 May., 2021.

E-mails: nardonengenharia@outlook.com; vitor.decampos@outlook.com; gabrielcicelini@gmail.com; weslleycds@petrobras.com.br; ruhamreis@ufu.br, valtair@ufu.br 
shell-and-tube heat exchangers with different frequencies for the probe absolute and differential channels. A better adequacy was found to be with the channels set at different frequencies, and the most appropriate values must be determined at the time of the test considering variations in the tubes, especially the magnetic permeability. Probe traction speed values higher than $568 \mathrm{~mm} / \mathrm{s}$ make the RFT reading of discontinuities difficult. Discontinuities less than $115 \mathrm{~mm}$ away from the support plate are not detected by the RFT absolute and differential channels, demanding the MIX channel, which subtracts the plate signal. In comparison with the IRIS, the RFT test, despite not intrinsically allowing the sizing of discontinuities, has been shown to be much faster in terms of scanning execution and with similar detection capacity.

Keywords: IRIS; RFT; Remote field; Non-destructive inspection; Heat exchangers.

\section{Introdução}

Caldeiras e trocadores de calor do tipo casco e tubos são equipamentos indispensáveis em diversos setores industriais, especialmente no setor petrolífero. Segundo Ginzel (2018), tubos metálicos são frequentemente usados em componentes de troca de calor, e pelo ambiente de operação eles podem sofrer vários danos, incluindo erosão e corrosão. Quando montados em uma unidade de troca de calor, os tubos são, em geral, acessíveis apenas pelo seu interior. Assim, a superfície externa dos tubos, muitas das vezes a mais deteriorada, geralmente não é acessível devido ao casco ao redor do trocador de calor ou aos tubos vizinhos que são montados tão próximos que o acesso externo é bastante limitado. Assim, vários métodos de inspeção não destrutiva com acesso interno aos tubos, tanto baseados em indução de correntes parasitas ou de campos magnéticos quanto como em ultrassom, têm sido utilizados com intuito de examinar equipamentos deste tipo, com destaque para as técnicas de Campo Remoto (RFT - Remote Field Testing) e de Sistema de Inspeção Rotativa Interna (IRIS - Internal Rotary Inspection System).

O RFT é comumente empregado para detectar descontinuidades internas ou externas em tubos de materiais ferromagnéticos. Além disso, oferece uma boa sensibilidade na detecção de descontinuidades volumétricas resultantes de corrosão, erosão, desgastes abrasivos e de outras formas de perda de massa (Ramos, 2015). Huang e Wang (2013) citam que o RFT é uma tecnologia especial do teste de Corrente Parasita (ECT - Eddy Current Testing) que utiliza as características da região de campo remoto das correntes parasitas (também conhecidas como correntes de Foucault) para detectar descontinuidades. Segundo os mesmos autores, o RFT foi aplicado inicialmente na inspeção interna de gasodutos de pequena espessura na década de 1950. Soares (2005) cita que os ensaios não destrutivos por correntes induzidas, caso do RFT e do ECT, são largamente empregados na indústria de transformações de metais, possibilitando resolver uma grande variedade de problemas de avaliação de materiais e produtos, assegurando uma qualidade uniforme nos produtos avaliados. No geral, estas técnicas permitem a inspeção de tubos de materiais eletricamente condutores, ferromagnéticos e não ferromagnéticos. Mas muitas vezes a implementação esbarra na complexidade de interpretação dos resultados por parte da equipe de inspeção.

O RFT consiste basicamente em uma sonda com uma bobina excitadora e uma bobina receptora. A bobina excitadora é energizada com uma corrente alternada de baixa frequência, gerando um campo magnético que se propaga axialmente pelo tubo inspecionado e chega à bobina receptora. Quando a espessura de parede do tubo diminui, ocorre uma variação no campo magnético nesta região, que por sua vez altera a fase e a amplitude do sinal captado pela sonda. Como o RFT utiliza baixas frequências de excitação, da ordem de centenas de Hertz, o campo magnético gerado consegue penetrar em todo o raio do tubo, fazendo com que tanto falhas internas quanto externas possam ser detectadas (Al-Qadeeb, 2005). Vale ressaltar que, dependendo da aplicação almejada e também do fabricante, o mercado oferece diferentes configurações de sondas para RFT, como, por exemplo, ilustrado esquematicamente na Figura 1 para o caso de duas bobinas excitadoras e uma bobina receptora.

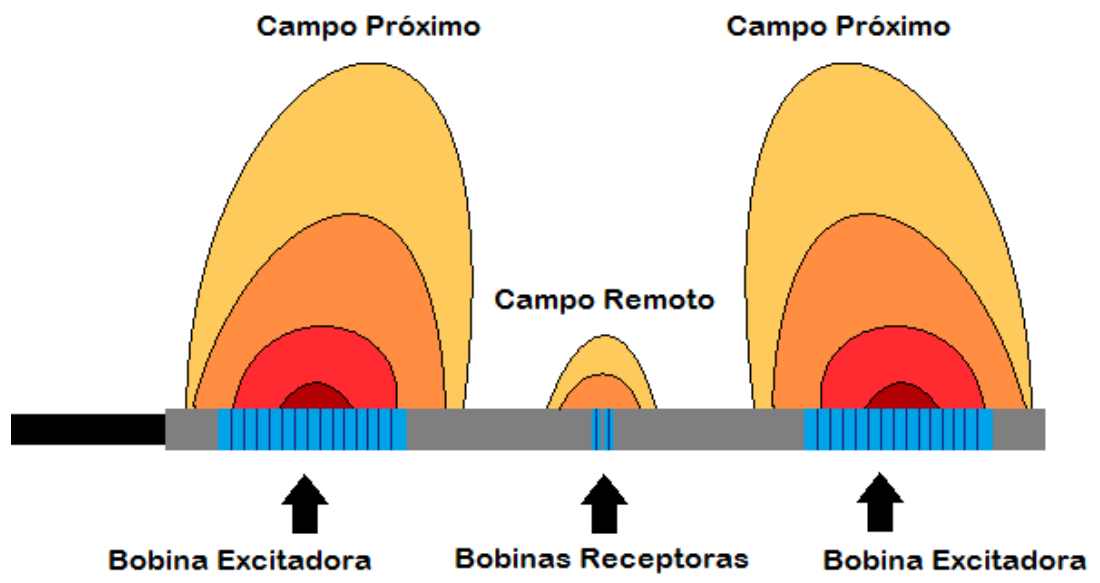

Figura 1. Esquema de uma sonda para RFT com duas bobinas excitadoras e uma receptora. 
Os resultados do ensaio são gerados à medida que a sonda é puxada ao longo do tubo em diferentes canais: um canal absoluto, geralmente usado para defeitos maiores e corrosão generalizada, um canal diferencial, usado para defeitos pontuais (pittings), e um canal MIX (mistura do absoluto e do diferencial), utilizado para auxiliar na deteç̧ão de defeitos próximo a chicanas e espelhos. Tipicamente são apresentados como resultados planos de tensão para cada um dos canais de operação, nos quais aparecem as alterações de fase e amplitude do sinal. Esses planos gráficos são comumente decompostos em seus eixos $X$ e $Y$ na forma de strip charts, cujo objetivo é facilitar a detecção de descontinuidades. Um exemplo geral de interface com resultados gerados pelo ensaio RFT é apresentado na Figura 2.

Para uma boa prática do ensaio, além da escolha da sonda, deve-se configurar adequadamente o equipamento e seu software, como pela escolha de uma frequência de excitação correta e mantendo uma velocidade de ensaio razoavelmente constante. Guérard et al. (2017), citam que a frequência de excitação em um ensaio RFT deve ser selecionada visando um bom ângulo de fase entre os defeitos a serem lidos, o que leva a um dimensionamento mais preciso da profundidade dos mesmos, respeitando a velocidade de ensaio máxima recomendada pela fabricante.

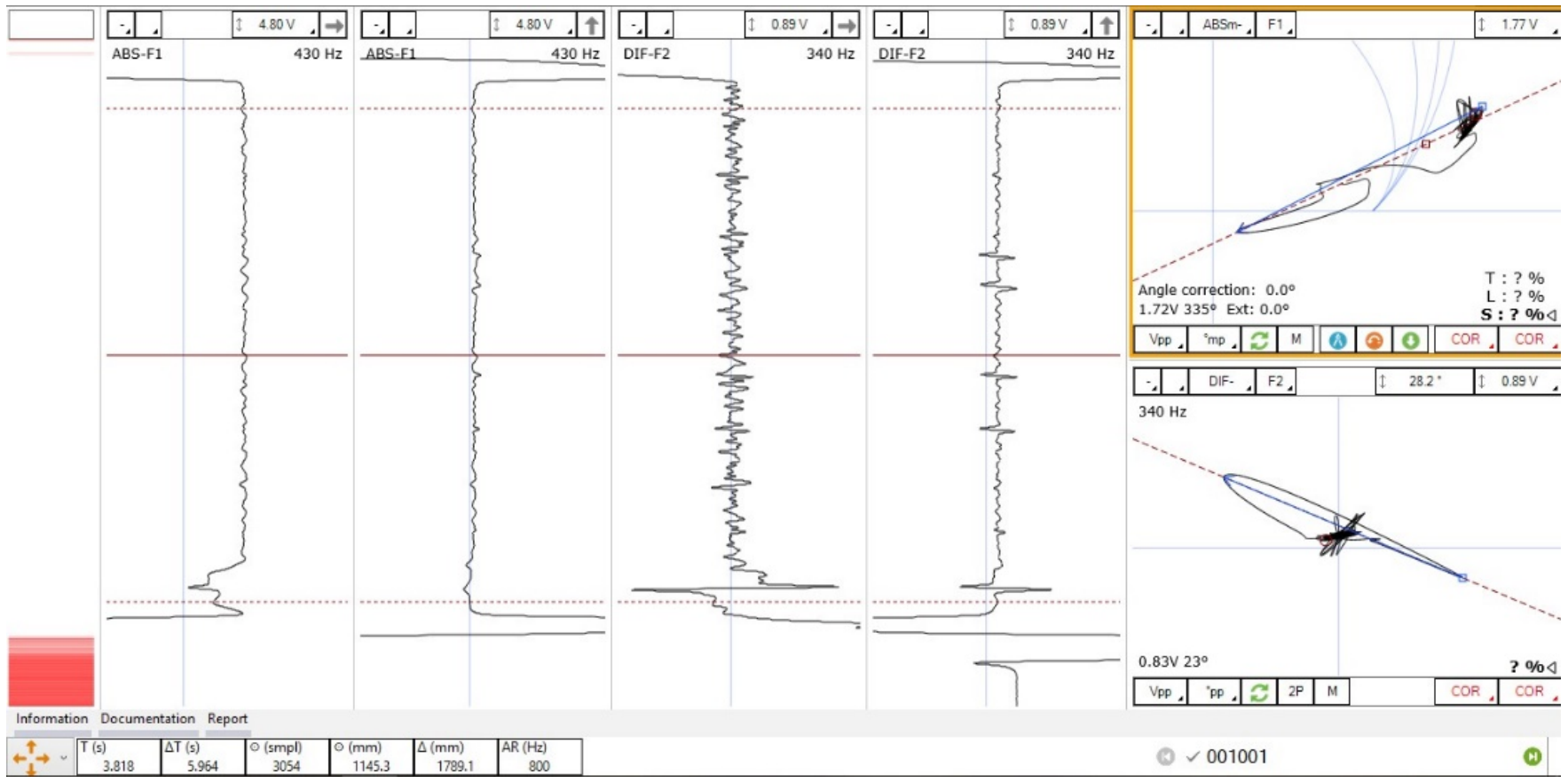

Figura 2. Interface do software ECTANE 2 da Eddyfi para o ensaio RFT. À direita observa-se os dois planos de tensão para os canais Absoluto e Diferencial e à esquerda os quatro strip charts correspondentes à decomposição desses planos em componentes $\mathrm{X}$ e $\mathrm{Y}$.

Segundo Ornelas (2017), o IRIS se baseia no ensaio de ultrassom por imersão, no qual se utiliza uma coluna d'água para transmitir o sinal ultrassônico até a peça a ser inspecionada. Mas neste caso, como ilustra sequencialmente a Figura 3, um sistema de rotação integrado, movido pelo próprio fluxo de água bombeado para dentro do tubo, gira um espelho acústico que reflete o pulso ultrassônico, inicialmente emitido paralelamente ao eixo axial do tubo, perpendicularmente à parede interna do tubo, direcionando-o assim em torno da circunferência da parede do tubo. O sinal é então refletido pelas paredes interna e externa do tubo, o que resulta, após processamento pelo software da técnica, em indicações de amplitude e tempo de propagação do som, o que permite determinar os diâmetros interno e externo do tubo e, assim, a espessura de sua parede, além de possíveis descontinuidades entre esta duas dimensões. É justamente a dinâmica de funcionamento, derivada do mecanismo de rotação, que dá nome ao ensaio. Como destacado por Ornelas (2017), conforme a sonda é puxada ao longo do tubo, o movimento giratório do espelho resulta em um percurso de varredura helicoidal, possibilitando o escaneamento completo do tubo.

Como ocorre em outras técnicas baseadas no ensaio por ultrassom, os resultados podem ser apresentados pelo software em diversas formas de visualização, sendo comum o espectro dos ecos sônicos ou ainda uma representação em escala de cor da superfície. Um exemplo geral de interface com resultados gerados pelo ensaio IRIS é apresentado pela Figura 4. 


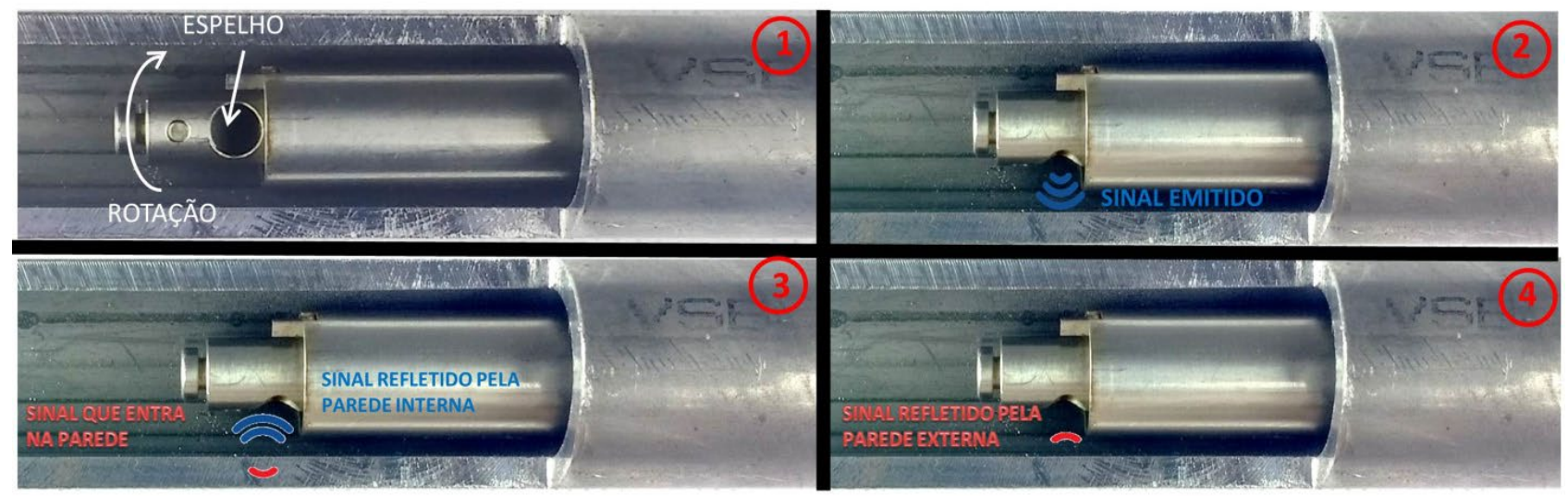

Figura 3. Sequência esquemática de propagação e reflexão de um pulso sônico no IRIS.

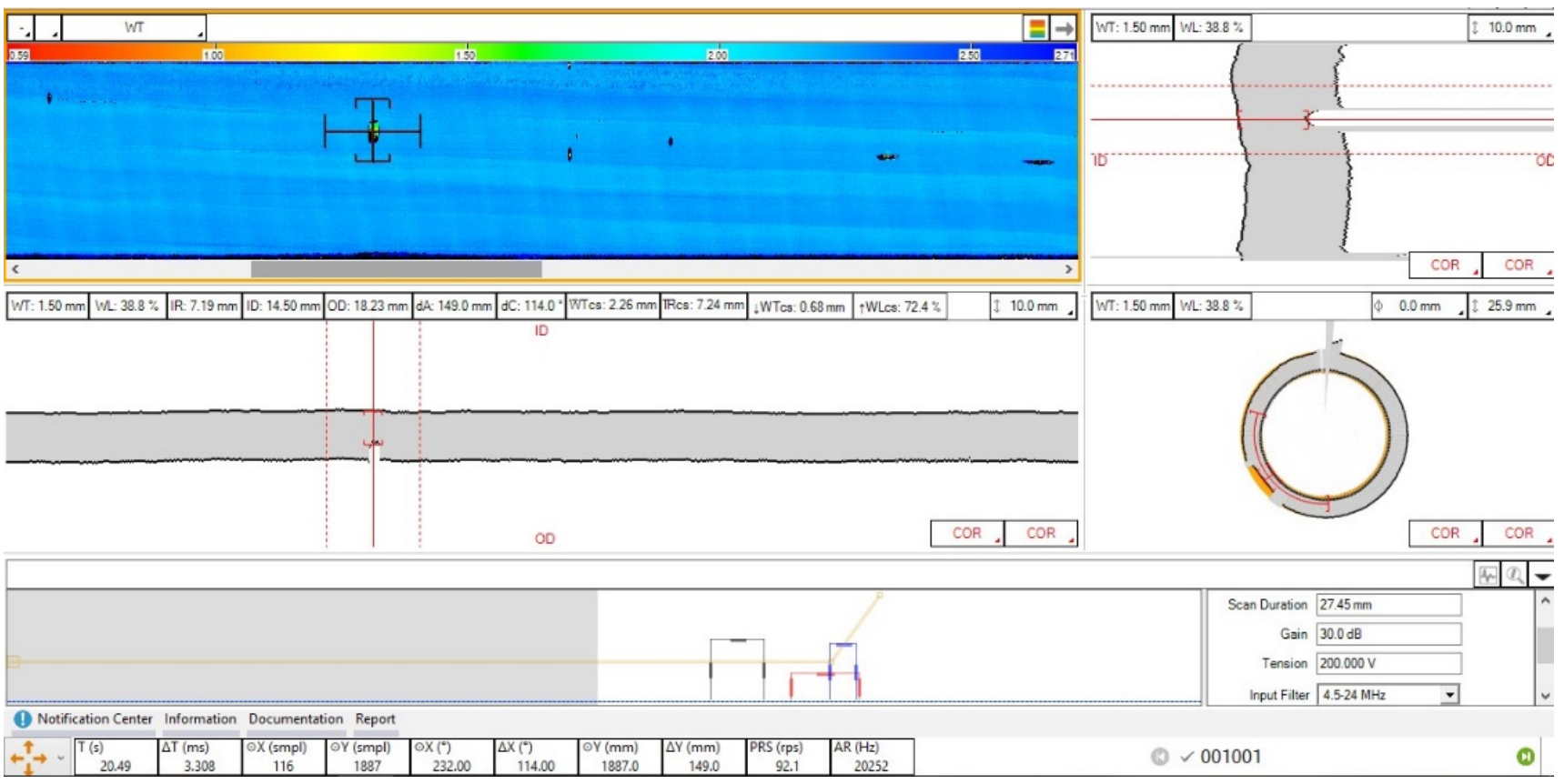

Figura 4. Interface do software ECTANE 2 da Eddyfi para o ensaio IRIS. Na parte inferior são apresentados os picos do pulso sônico; à direita uma planificação da parede do tubo e sua representação circunferencial, e acima uma representação em escala de cor do tubo que foi inspecionado indicando a forma e a localização dos defeitos.

As vantagens e as desvantagens de uma técnica de inspeção em feixes tubulares de trocador de calor estão diretamente relacionadas ao tipo de material que esse feixe é construído, ferromagnético ou não-ferromagnético, e ao tipo de defeito que se deseja investigar. Os defeitos mais comuns encontrados em feixes tubulares são: corrosão por pittings internos e externos; trincas axiais e circunferenciais; corrosões internas e externas (Nogueira, 2015).

Como citado anteriormente, a técnica de inspeção por RFT não é capaz de realizar ensaios em tubos não-ferromagnéticos, o que já pode-se considerar como uma desvantagem da técnica, enquanto o ensaio por IRIS consegue realizar a inspeção em uma ampla variedade de materiais. Quando considerado o tipo de descontinuidades que se deseja encontrar, as duas técnicas possibilitam resultados satisfatórios para alguns defeitos e insatisfatórios para outros, como mostra a Tabela 1.

Tabela 1. Aplicações das técnicas IRIS e RFT (baseado em Nogueira (2015)).

\begin{tabular}{cccccccc}
\hline & Pitting Interno & $\begin{array}{c}\text { Pitting } \\
\text { Externo }\end{array}$ & Trinca Axial & Trinca Circunferencial Corrosão Interna Corrosão Externa & $\begin{array}{c}\text { Corrosão } \\
\text { nas chicanas }\end{array}$ \\
IRIS & Ótimo & Ótimo & NA & NA & Ótimo & Ótimo & Ótimo \\
RFT & $+/-$ & $+/-$ & $+/-$ & NA & Ótimo & Ótimo & $+/-$ \\
\hline
\end{tabular}


Certamente, a prática do RFT, se comparada com o IRIS, notadamente no Brasil, ainda é pouco difundida quando da realização de inspeções, apesar de suas potenciais vantagens e possibilidades para facilitar a inspeção e redução de parte dos custos envolvidos. Isso provavelmente se deve a necessidade de grande experiência/conhecimento para a análise dos sinais e também ausência de investimento das empresas nessa técnica, fatores que acabam potencializando um ao outro.

Assim, este trabalho visa a contribuir para o entendimento da técnica RFT e da influência de seus parâmetros de operação, como frequência de excitação e velocidade de puxada da sonda, e efeito da placa de suporte na leitura e interpretação dos resultados, bem como avaliar seu desempenho frente ao IRIS com relação a diferentes tipos de descontinuidades.

\section{Metodologia}

Para os estudos da técnica RFT, fez-se necessária a produção de um tubo padrão de calibração, conforme orientações contidas no manual do fabricante do equipamento e ressalvas de norma para padrões de RFT (ASTM, 2019). Assim, foi elaborado o projeto de um tubo padrão com $1000 \mathrm{~mm}$ de comprimento dentro de parâmetros de tubos encontrados comumente em trocadores de calor do tipo casco e tubos utilizados em refinarias de petróleo, ou seja, constituído em aço carbono com $19,05 \mathrm{~mm}$ de diâmetro externo e 14,15 mm de diâmetro interno. O desenho do tubo padrão elaborado está disposto na Figura 5. Para este tubo padrão, foram criadas duas descontinuidades maiores com abrangência circunferencial de $360^{\circ}$ (uma ranhura com $40 \%$ e outra com $60 \%$ da espessura da parede do tubo), um furo passante, um furo de fundo plano com perda de espessura de $60 \%$, 4 furos com perda de $20 \%$ defasados em $90^{\circ}$ entre si e uma placa de suporte (função da chicana do trocador de calor).
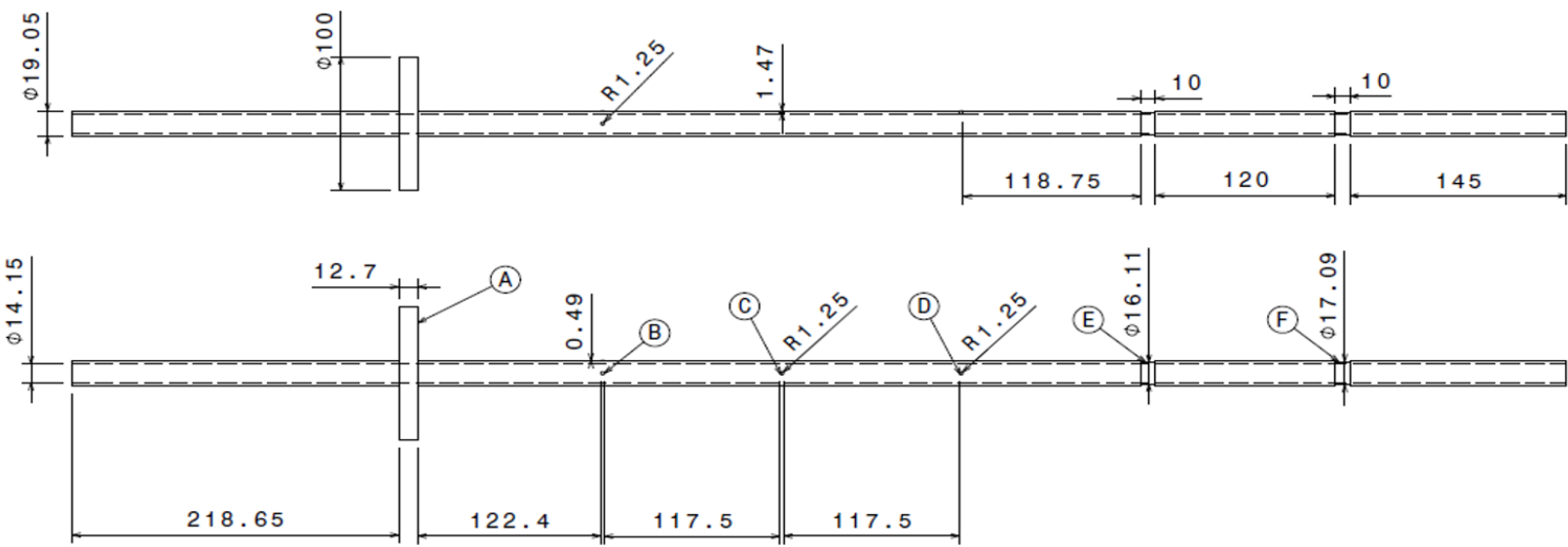

A - Chicana

B - 4 furos com perda de espessura de $20 \%$ e defasados em $90^{\circ}$

D - Furo Passante

C - Furo de fundo plano com $60 \%$ de perda de espessura

E - Ranhura com perda de espessura de $60 \%$ e circunferencial

F - Ranhura com perda de espessura de $40 \%$ e circunferencial

Figura 5. Desenho do tubo padrão de calibração para o ensaio RFT (dimensões em mm).

Visando à manutenção da velocidade de puxada da sonda durante os ensaios com RFT, foi idealizado e construído (por usinagem e manufatura aditiva, no caso, Fusion Deposition Modelling) um tracionador (Figura 6) a partir de um motor de passo com torque de $15 \mathrm{~kg}^{*} \mathrm{~cm}$. Para o controle do motor e regulagens finas de velocidade foi incorporada ao conjunto uma fonte DC e um gerador de pulsos de corrente alternada ajustada por meio de um potenciômetro, resultando em um equipamento funcional e de baixo custo.
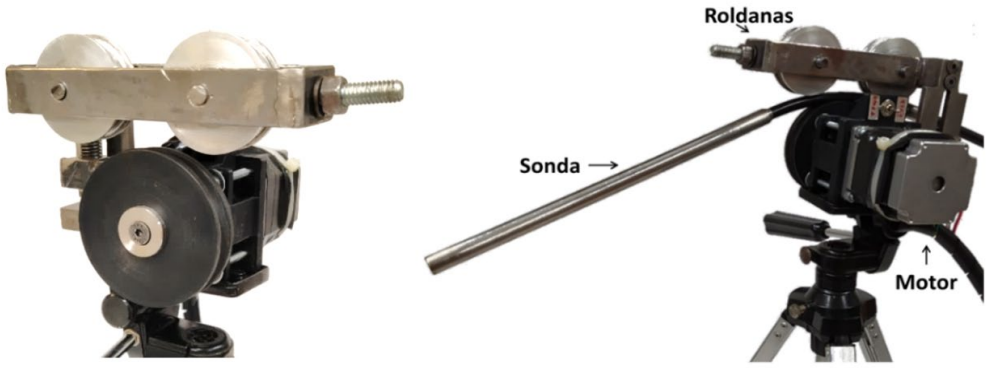

Figura 6. Tracionador para auxílio do ensaio RFT. 
O equipamento utilizado para a realização dos ensaios com RFT e IRIS foi o ECTANE 2 da Eddyfi ${ }^{\circledR}$, com conexão via cabo de rede para interface com o usuário. No caso do RFT, foi utilizada uma sonda Dual Drive de cabo rígido de diâmetro compatível com os tubos analisados. No caso do IRIS, foi utilizada uma sonda com turbina acionada por um sistema de bombeamento de água e de diâmetro também compatível com os tubos analisados. A Figura 7 apresenta os principais itens utilizados em cada teste.

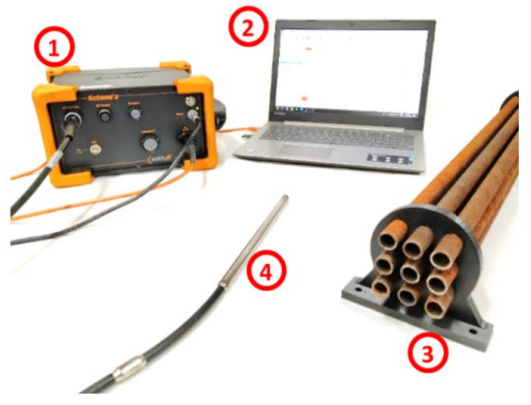

1 - Equipamento Magnify Ectane $2^{\circledR}$

2 - Computador

3 - Feixe tubular com tubos reais

4 - Sonda para ensaio de RFT

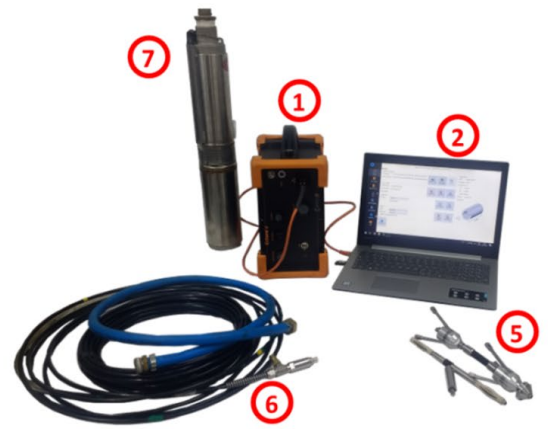

5 - Conjunto sonda para ensaio de IRIS

6 - Conjunto de mangueiras e conduítes para ensaio IRIS

7 - Bomba d'água para ensaio IRIS

Figura 7. (Esquerda) Equipamento geral para o ensaio RFT; (Direita) Equipamento geral para o ensaio IRIS.

A calibração do sistema RFT foi realizada seguindo recomendações do fabricante e também normatizadas (ASME, 2019), com atenção para o distanciamento dos tubos analisados com relação a possíveis fontes de interferência, como o contato ou proximidade com objetos metálicos. As frequências de excitação das bobinas também foram selecionadas de forma a não coincidir com os harmônicos da rede elétrica de alimentação $(60 \mathrm{~Hz})$. O procedimento foi realizado a uma velocidade constante de $300 \mathrm{~mm} / \mathrm{s}$. Os parâmetros para a validação da calibração dos canais absoluto e diferencial do RTF foram:

No canal Diferencial:

- $\quad$ Para o furo passante: Fase de $90^{\circ}$ e amplitude de 1 Volt;

- $\quad$ Furos de $20 \%$ : Defasados entre $60^{\circ}$ e $70^{\circ}$ com relação ao furo passante;

- $\quad$ Placa de suporte: sinal traçado na transversal entre o segundo e quarto quadrante do plano de voltagem. No canal Absoluto:

- $\quad$ Placa de suporte: Sinal com amplitude de 1 volt, paralelo ao eixo horizontal e com origem no ponto nominal teórico de operação (ponto $[1,0]$ );

- $\quad$ Ranhuras: Fase dos sinais defasadas cerca de $1^{\circ}$ para cada $1 \%$ de diferença na perda de espessura.

A calibração do sistema IRIS foi realizada com o mesmo tubo padrão do RFT. Durante o procedimento de calibração desta técnica foram verificadas e ajustadas a velocidade de rotação da turbina, que é proporcional à vazão de água imposta pela bomba, para que esta se aproximasse do valor inserido no software, e também os gates de leitura dos picos do pulso sônico da parede interna e externa. Ademais, foram realizados ajustes finos no ganho do sinal a fim de melhorar a relação sinal/ruído.

\subsection{Avaliação das características do RFT}

Alguns parâmetros críticos para a realização do ensaio RFT foram estudados de forma mais detalhada. Dentre esses, incluem-se a velocidade da sonda, a frequência de excitação e a presença de descontinuidades próximas às placas de suporte. Essas análises foram realizadas no tubo de calibração, posto que suas descontinuidades são conhecidas e mais facilmente identificadas.

Nesses ensaios foram avaliados, principalmente, os ângulos de fase de defeitos conhecidos. O software que processa os dados coletados na aquisição relaciona, por meio de parâmetros do tubo de calibração, ângulos de fase a percentagens de perda de espessura.

\subsubsection{Velocidade}

Através do controle de velocidade do tracionador foram realizados ensaios com variação de velocidade da sonda. A velocidade real foi avaliada a partir do comprimento do tubo e do tempo de aquisição do sinal. As velocidades estudadas foram: 
$134,218,230,300,568$ e 764 mm/s. O intuito desse estudo foi verificar possíveis variações na leitura dos sinais de aquisição, como fase e amplitude, em relação à variação da velocidade, uma vez que as operações em campo podem levar a variações na velocidade de aquisição, seja pelo atrito interno entre os diferentes tubos e a sonda, falhas no sistema de tracionamento ou ainda devido à necessidade de realizar o ensaio manualmente. Essas análises foram feitas unicamente pela leitura do sinal do furo passante em ambos os canais (Absoluto e Diferencial).

Foram feitos, em complemento, alguns testes de operação manual da sonda, puxando-a pelo cabo com velocidade aproximadamente constante, para avaliar os efeitos da diferença entre puxar manualmente e com o uso do tracionador. Por fim, foi empregada uma velocidade muito acima do que se considera natural para um ensaio RFT (acima de $1000 \mathrm{~mm} / \mathrm{s}$, de forma manual). Esses resultados devem ser atrelados à frequência de aquisição, um parâmetro que determina a definição do sinal e está diretamente relacionado à velocidade de puxada da sonda, já que, quanto mais rápido o ensaio, maior deve ser a frequência de aquisição.

O estudo da influência da velocidade foi feito com uma frequência de aquisição fixa de $800 \mathrm{~Hz}$, o que é condizente com a velocidade de $300 \mathrm{~mm} / \mathrm{s}$ utilizada na calibração segundo o fabricante do equipamento de inspeção por RFT utilizado.

\subsubsection{Frequência}

Nessa parte do ensaio foi avaliada a influência da frequência de excitação na aquisição do sinal e também como a variação dos tubos pode influenciar nos sinais obtidos.

Inicialmente, estabelecida uma frequência intermediária de $380 \mathrm{~Hz}$ (sugerida por técnicos da Eddyfi); foi feita a calibração do equipamento no tubo padrão. Após a leitura dos dados e utilizando o mesmo tubo de calibração, realizaram-se então ensaios com frequências ligeiramente maiores e menores do que os $380 \mathrm{~Hz}$ inicialmente utilizados, visando a adequar melhor as características dos sinais coletados aos parâmetros dispostos no item 2, ou seja, foi analisado predominantemente o ângulo de fase entre os defeitos de interesse. Essa busca também foi realizada com duas frequências diferentes simultâneas, uma para cada canal do equipamento. A Tabela 2 mostra todas as frequências utilizadas em cada canal

Para um bom resultado do ensaio RFT, deve-se obter $1^{\circ}$ para cada $1 \%$ de diferença na perda de espessura para o canal absoluto. Ou seja, como no canal absoluto analisou-se a defasagem entre as ranhuras de $40 \%$ e de $60 \%$, a melhor avaliação ocorre com o resultado mais próximo de $20^{\circ}$. Já considerando o canal diferencial, o melhor resultado ocorre quando a defasagem entre o furo passante e os 4 furos de base reta esteja entre $60^{\circ}$ e $70^{\circ}$.

Em seguida, esse processo de aquisição de dados foi repetido em um tubo de ensaio escolhido fornecido por uma empresa do setor de óleo e gás, esses tubos possuem descontinuidades pré-fabricadas e conhecidas. O material de composição desses tubos é aço carbono, os quais possuem as mesmas dimensões circunferenciais do tubo de calibração.

Tabela 2. Frequências de excitação para o ensaio RFT.

$\begin{array}{ccc}\text { Ensaio } & \text { Canal } & \text { Frequência } \\ 1 & \text { ABS } & 380 \mathrm{~Hz} \\ & \text { DIF } & \\ 2 & \text { ABS } & 400 \mathrm{~Hz} \\ & \text { DIF } & 405 \mathrm{~Hz} \\ 3 & \text { ABS } & 315 \mathrm{~Hz} \\ & \text { DIF } & 400 \mathrm{~Hz} \\ & \text { ABS } & 280 \mathrm{~Hz} \\ & \text { DIF } & 410 \mathrm{~Hz} \\ \end{array}$

Os ensaios nesse tubo visaram à busca por frequências de excitação da sonda adequadas à realização do ensaio e que compensassem a menor atenuação do campo eletromagnético provocada pela corrosão nele existente, ou seja, frequências que tornassem os sinais de leitura desse tubo próximos daquilo que foi lido com o tubo de calibração. Quanto mais próxima a configuração do sinal for da configuração do sinal de calibração, mais correta está a frequência de excitação. Como parâmetro para verificar se a frequência usada está ou não adequada, o sinal da placa de suporte no canal Absoluto é transportado de volta para o seu ponto de operação nominal, ou seja, o sinal da placa no tubo a ser ensaiado é normalizado em relação ao sinal de calibração. Uma boa prática adotada para o RFT entre os inspetores é assumir que, caso o sinal rotacione mais de $30^{\circ}$ no plano de voltagem durante esse procedimento de ajuste, uma compensação de frequência deve ser realizada. A Figura 8 mostra um sinal em que a frequência não está adequada para normalização, pois o valor de rotação é de $32,9^{\circ}$, acima dos $30^{\circ}$ recomendados. A Figura 9 mostra agora um sinal adquirido em que se é possível normalizar e obter um ângulo de correção aceitável, ou seja, menor que $30^{\circ}$. 


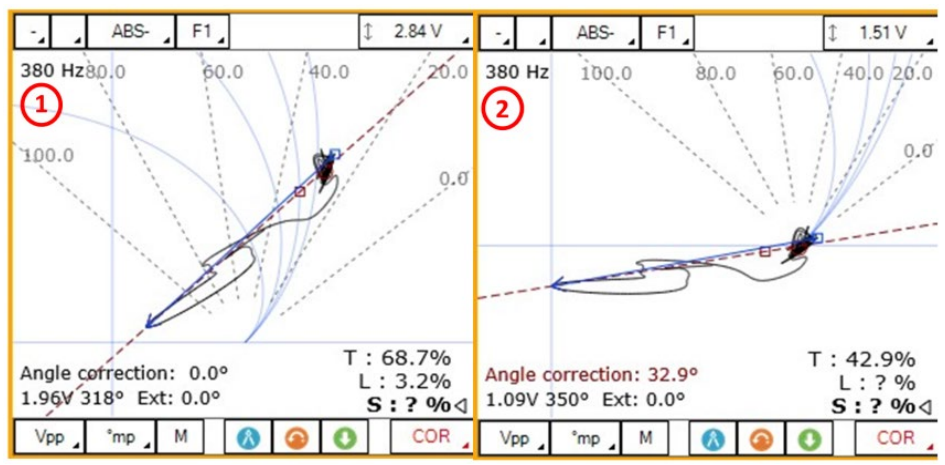

Figura 8. 1 - Sinal adquirido sem normalização. 2 - Sinal normalizado com ângulo de correção errado.

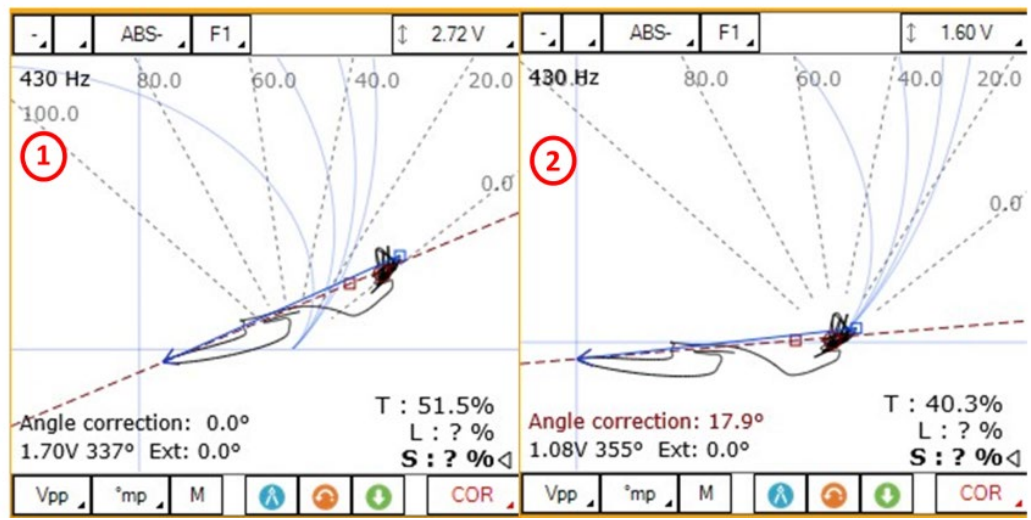

Figura 9.1 - Sinal adquirido sem normalização. 2 - Sinal normalizado corretamente com ângulo de correção menor que $30^{\circ}$.

\subsubsection{Proximidade da placa de suporte}

Trocadores de calor do tipo casco e tubos são construídos por espelhos, estruturas que sustentam os tubos em suas extremidades e chicanas, ou placa de suporte, as quais além de dar sustentação ao feixe tubular proporcionam o direcionamento do fluxo do fluido externo ao tubo, proporcionando assim uma melhor troca térmica no sistema. Esse redirecionamento do fluido externo ao tubo gera mudanças na velocidade desse fluido e como a placa é uma barreira física, esse mesmo fluido gera também um aumento de pressão localizada na placa de suporte, esses fenômenos favorecem a aceleração de mecanismos de corrosão, a detecção de defeitos próximos a essas estruturas é de primordial importância, para a realização de uma inspeção confiável, já que a placa de suporte muda a permeabilidade magnética do tubo no local em que está fixada e gera dificuldades na leitura dos dados do ensaio. Por isso, realizou-se um estudo de deteç̧ão de furo passante próximo a uma placa de suporte que simula uma chicana ou espelho. O procedimento de ensaio seguiu a metodologia de aquisição de dados anteriormente discorrida e para este estudo não foi utilizada mixagem de canais. A placa de suporte utilizada foi posicionada inicialmente sobre o furo, depois próxima à borda do furo (Figura 10) e por fim afastada constantemente da borda do furo até que fosse obtida uma leitura completa deste defeito. Os dados de leitura do furo no canal diferencial foram registrados para cada distância em que a placa foi posicionada.

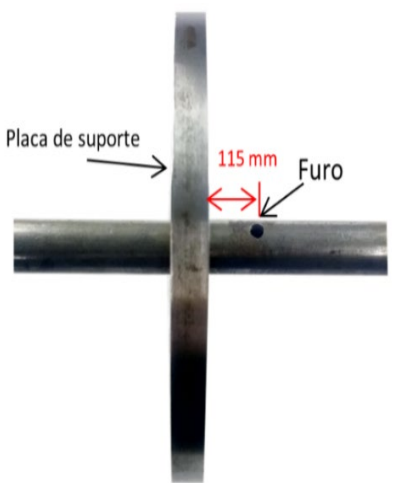

Figura 10. Posicionamento da placa de suporte próxima à borda do furo passante do tubo de calibração. 


\subsection{Avaliação do comparativo IRIS-RFT}

$\mathrm{Na}$ fase de estudos quantitativos, foi realizada uma bateria de ensaios IRIS visando à obtenção de dados para comparação entre as duas técnicas. As descontinuidades e a espessura nominal do tubo padrão foram verificadas e comparadas com os valores retornados pelo RFT para este mesmo tubo.

Após essa etapa, realizaram-se ensaios IRIS nos 5 tubos de trocador de calor (já supracitados em 2.1.2), fornecidos por uma empresa do ramo de óleo e gás, com descontinuidades de interesse de diferentes formatos. A realização do IRIS se deu com sonda sendo puxada manualmente, utilizando o mesmo equipamento (ECTANE 2 da Eddyfi ${ }^{\circ}$ ), sendo a sonda IRIS fornecida pela mesma empresa citada anteriormente. O motivo de não se usar o tracionador para esses exames foi a necessidade de uma velocidade bastante reduzida, além de pequenos ajustes, para evitar a ocorrência de bolhas de ar dentro do tubo analisado, que poderiam dificultar a interpretação dos resultados.

Em seguida, foram realizados os ensaios RFT por meio da calibração do equipamento no tubo padrão. Finalizado o processo de calibração, foram coletados os sinais tanto para o tubo de calibração quanto para os cinco tubos supracitados, mantendo sempre a velocidade constante da sonda, utilizando o tracionador configurado em aproximadamente $300 \mathrm{~mm} / \mathrm{s}$.

As descontinuidades de ambos os tubos foram comparadas para as duas técnicas, sobretudo as específicas de interesse. Além de comparar todas as descontinuidades do tubo padrão, foram confrontados: rasgos longitudinais, rebaixos e ranhuras disformes, furos opostos circunferencialmente, furos de tamanho reduzido e furos em sequência. Essas descontinuidades foram estudadas pelo fato de, em suas particularidades, apresentarem dificuldade de leitura em algum dos dois métodos. Por vezes foi necessário realizar a normalização do sinal RFT adquirido, devido às diferenças entre os tubos. Nesses casos a normalização foi realizada preferencialmente pelo sinal da placa de suporte, dada a dificuldade em encontrar um ponto de espessura nominal nas leituras. A leitura dos defeitos se deu no canal apropriado (diferencial para descontinuidades pontuais e absoluto para descontinuidades mais longas ou circunferenciais). Conforme visto nas Figuras 8 e 9, a normalização é um processo que demanda certo conhecimento por parte do operador e, como esse assunto foge da proposta deste artigo, ele será assunto de um próximo trabalho.

\section{Resultados}

\subsection{Avaliação do RFT}

\subsubsection{Velocidade}

Os ensaios realizados demonstraram que, para pequenas variações de velocidade de puxada da sonda, a leitura de perda de espessura (determinada pela fase do sinal) pouco varia, sendo observadas alterações mais significativas na amplitude do sinal. Observou-se também que, para velocidades inferiores à de calibração, a qualidade do sinal melhora devido ao aumento da resolução, ao passo que a amplitude aumenta e o ângulo de fase sofre pequenas variações. Por outro lado, para velocidades superiores à de calibração, a resolução do sinal diminui, assim também como a amplitude do sinal. O formato do sinal é distorcido, com aumento do ângulo de fase e consequente detrimento de leitura da perda de espessura pelo software. Esses resultados foram obtidos para ambos os canais de operação utilizados, conforme ilustra a sequência de imagens da Figura 11 , onde os números de 1 a 6 identificam as velocidades utilizadas de $135 \mathrm{~mm} / \mathrm{s}, 218 \mathrm{~mm} / \mathrm{s}, 230 \mathrm{~mm} / \mathrm{s}, 300 \mathrm{~mm} / \mathrm{s}, 568 \mathrm{~mm} / \mathrm{s}$ e $764 \mathrm{~mm} / \mathrm{s}$, respectivamente.

Constatou-se que, para variações estritamente pequenas com relação à velocidade utilizada na calibração, a variação de leitura de perda de espessura é quase insignificante, pois a fase dos defeitos pouco muda. A informação do comprimento do tubo que o software retorna ao final do ensaio sofre alteração direta com a frequência de aquisição. A amplitude do sinal é influenciada pela velocidade da sonda; com relação à velocidade de calibração, ao acelerar a puxada, a amplitude diminui, e ao desacelerar, a amplitude aumenta (Figura 12 item 1). Com relação ao ângulo de fase, observou-se que desacelerar a puxada da sonda praticamente não influenciou na orientação do sinal. Por outro lado, uma puxada com velocidade maior do que a de calibração resultou em diminuição do ângulo de fase e eventualmente na ausência de leitura de perda de espessura (Figura 11 item 6). 


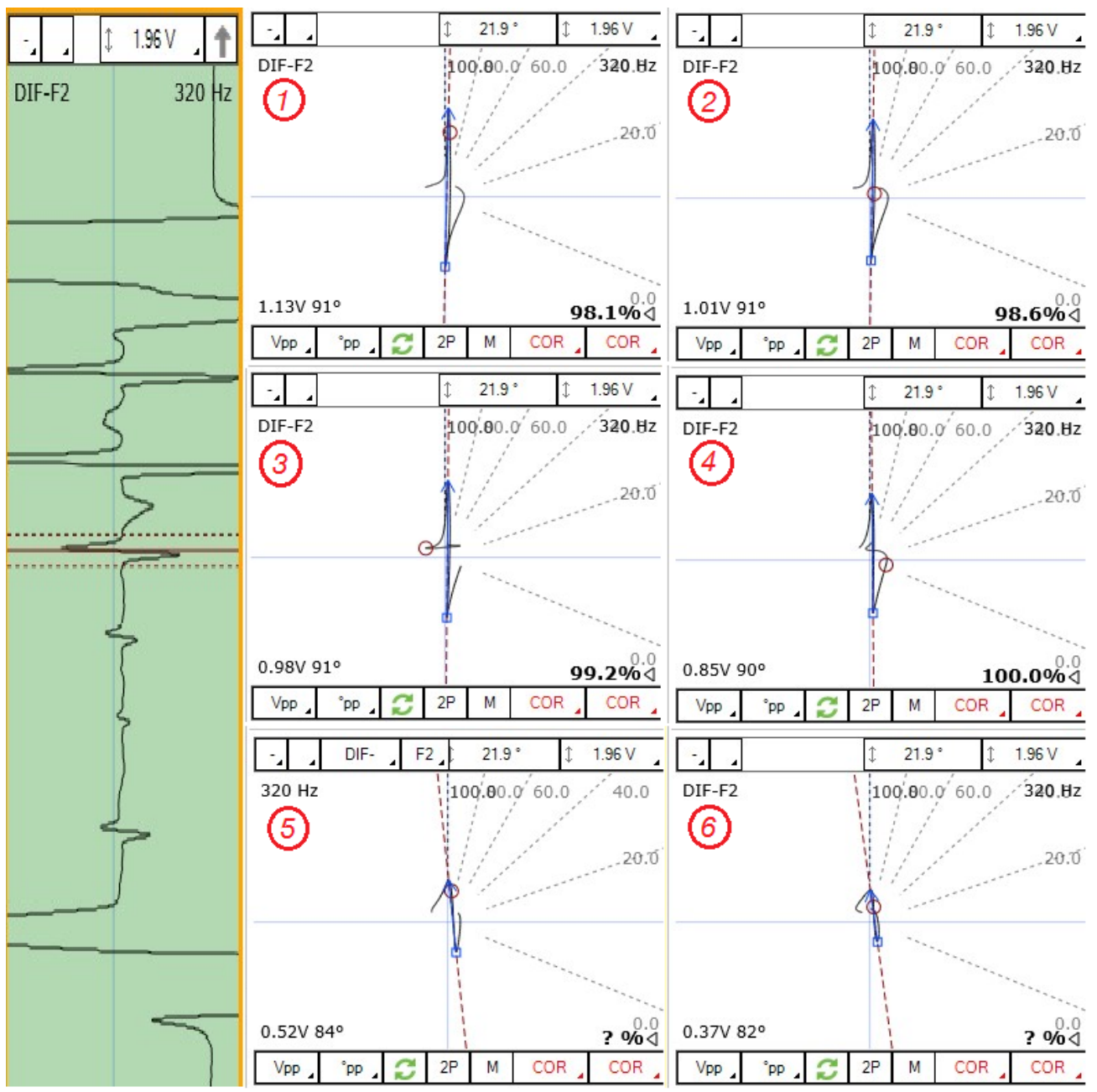

Figura 11. Sequência de experimentos relacionado amplitude do sinal no canal diferencial e velocidade de puxada da sonda no ensaio RFT, sinal de um furo passante no tubo.
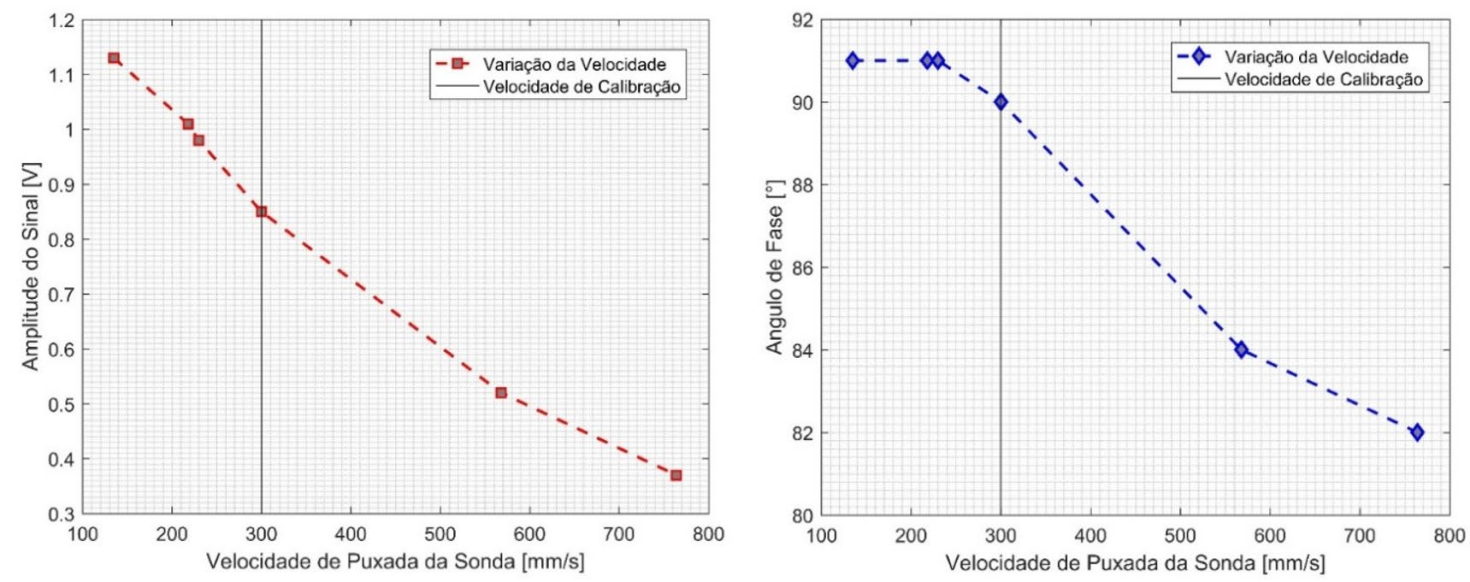

Figura 12. Gráficos de efeito da velocidade de puxada da sonda RFT sobre a amplitude e sobre o ângulo de fase do sinal em um furo passante no tubo padrão.

Tracionar a sonda com uma velocidade extremamente reduzida mostrou-se uma alternativa igualmente pouco atrativa: nesse caso, apesar de o ângulo de fase praticamente não sofrer alteração e seguir o que foi discorrido acima, pode-se concluir, pela imagem do sinal de uma descontinuidade disposta na Figura 13, que muito se perde em questão de qualidade de sinal, uma vez que as linhas que determinam o mesmo ficaram ruidosas. 
A partir desses resultados pode-se concluir que o cenário ideal para a realização do ensaio RFT é calibrar o sistema a uma dada velocidade e então reduzir sensivelmente a velocidade para a realização dos ensaios em si, com o intuito de garantir a amplitude adequada das leituras e uma melhor detecção das descontinuidades. Os resultados com o uso repetitivo do tracionador produzido demonstraram que é possível manter uma velocidade razoavelmente constante e satisfatória para a análise, garantindo boa repetibilidade para os dados de um mesmo tubo, por exemplo.

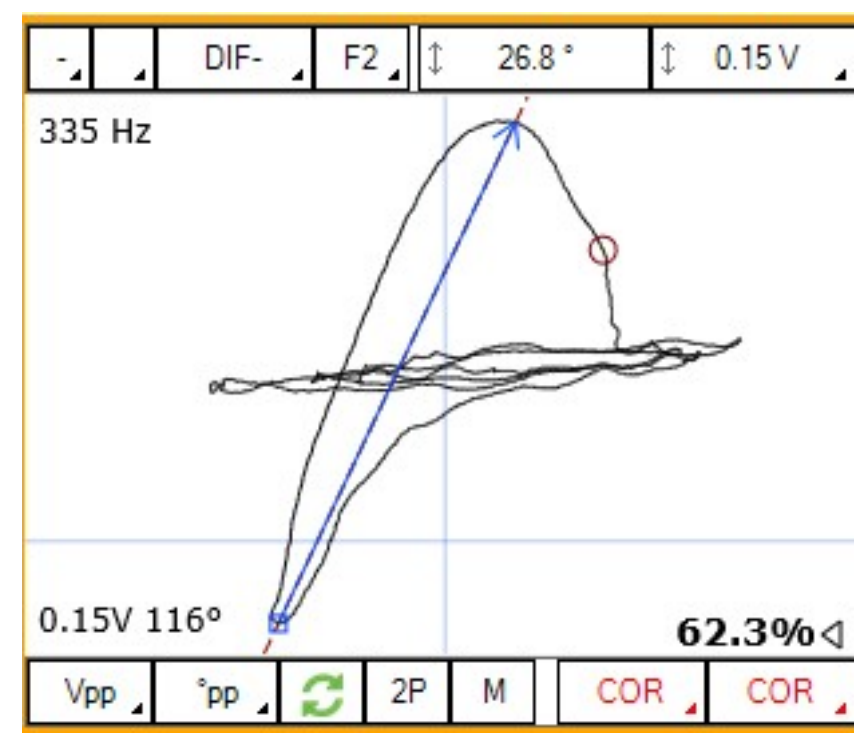

Figura 13. Aspecto de um defeito no canal diferencial com velocidade de puxada da sonda extremamente reduzida $(62,5 \mathrm{~mm} / \mathrm{s})$.

\subsubsection{Frequência}

A Tabela 3 mostra os resultados encontrados com a variação da frequência em cada canal no ensaio RFT. Como pode ser visto, o melhor cenário está em utilizar frequências diferentes para cada canal. O uso de uma única frequência de excitação foi descartado visando à obtenção de uma calibração mais precisa e dentro dos parâmetros desejados.

Tabela 3. Otimização da frequência de excitação da sonda RFT para adequação ao tubo de calibração.

\begin{tabular}{|c|c|c|}
\hline Frequência & $\begin{array}{c}\text { ABS } \\
\text { Fase entre } 40 \%-60 \%\end{array}$ & $\begin{array}{c}\text { DIF } \\
\text { Fase entre } 100 \%-20 \%\end{array}$ \\
\hline $380 \mathrm{~Hz}$ & 180 & 760 \\
\hline $400 \mathrm{~Hz}$ & 190 & 790 \\
\hline $\begin{array}{l}\text { ABS } \rightarrow 405 \mathrm{~Hz} \\
\mathrm{DIF} \rightarrow 315 \mathrm{~Hz}\end{array}$ & 20 은 & $67^{\circ}$ \\
\hline $\begin{array}{l}\mathrm{ABS} \rightarrow 400 \mathrm{~Hz} \\
\mathrm{DIF} \rightarrow 280 \mathrm{~Hz}\end{array}$ & 190 & 610 \\
\hline $\begin{array}{l}\mathrm{ABS} \rightarrow 410 \mathrm{~Hz} \\
\mathrm{DIF} \rightarrow 260 \mathrm{~Hz}\end{array}$ & 20 - & 570 \\
\hline
\end{tabular}

Como mencionado anteriormente, a busca da frequência correta para realizar o ensaio RFT está relacionada à correta leitura das descontinuidades. A Figura 14 exemplifica um sinal com frequência inadequada e outro sinal do mesmo tubo com frequência adequada. Como observado, as posições do sinal nos quadrantes 1 e 2 estão corretas. Os sinais se desenvolveram nas coordenadas 1,0 do plano de voltagem, mostrando que a frequência de ensaio está correta. 0 sinal não precisa sair exatamente em cima desse ponto, mas a sua variação não pode ser muito grande. Os sinais nos quadrantes 3 e 4 mostram um sinal extremamente fora da coordenada correta do plano de voltagem, com o software mostrando uma correção de $-106.6^{\circ}$, 0 que indica que a frequência de ensaio não condiz com a permeabilidade magnética do tubo. Quando esse ângulo de correção se torna exagerado, acima de $+/-30^{\circ}$ segundo o manual do equipamento, a normalização do sinal passa a ser inadequada e um novo ensaio passa a ser necessário. 


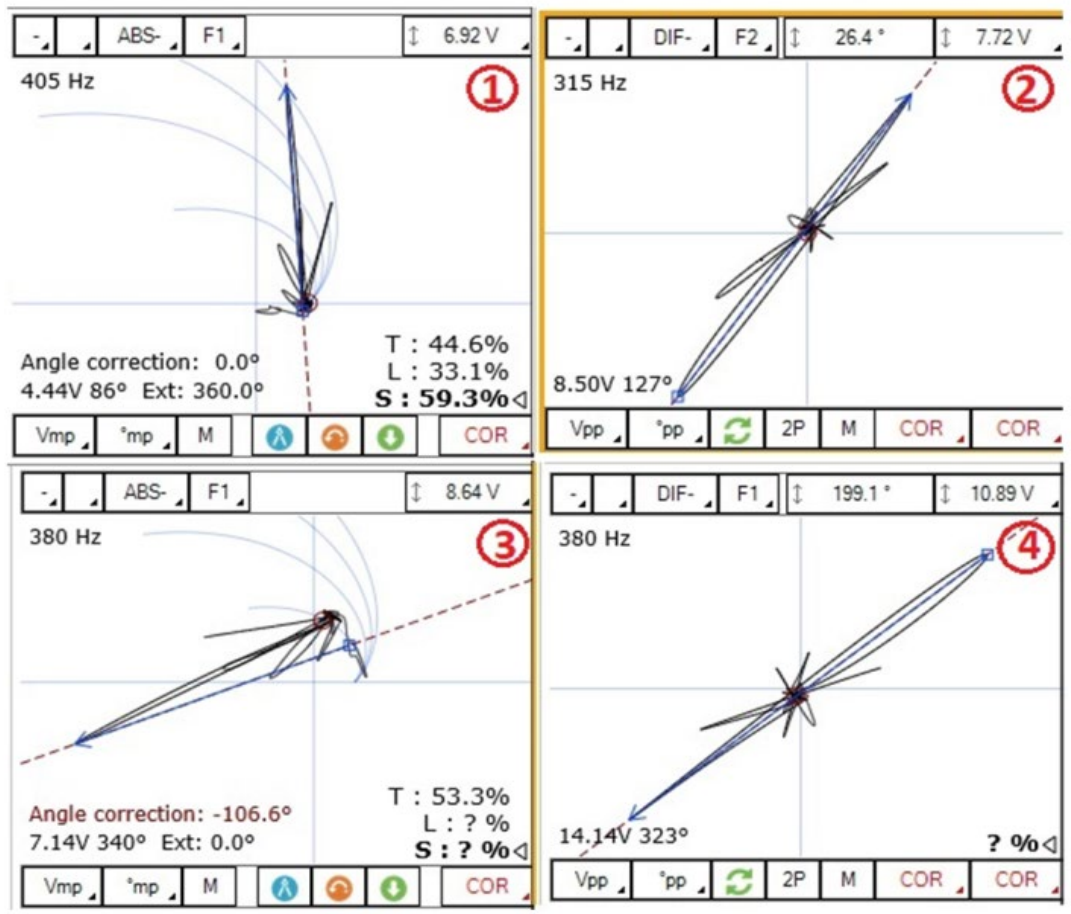

Figura 14. 1 - Sinal Absoluto com frequência correta $(405 \mathrm{~Hz}) ; 2$ - Sinal Diferencial com frequência correta (315 Hz); 3 - Sinal Absoluto com frequência inadequada $(380 \mathrm{~Hz}) ; 4$ - Sinal Diferencial com frequência inadequada $(380 \mathrm{~Hz})$.

A restrição do ângulo de rotação em 30 graus se dá para a compensação da frequência após a realização da calibração. A Tabela 3 está com a frequência ideal (dual frequency) para a realização da calibração utilizando o tubo de calibração produzido para este estudo e a frequência correta varia de acordo com a variação do tubo padrão, isso ocorre por causa da variação da permeabilidade magnética de cada material.

Esse estudo mostra que a correta frequência de ensaio é necessária para que o sinal a ser analisado seja desenvolvido no local correto do plano de voltagem e que suas alterações são de extrema importância para a correta interpretação dos resultados do ensaio RFT. Após a frequência ótima ter sido encontrada, ela foi utilizada nos demais ensaios RFT em termos comparativo com o IRIS tomado referência.

\subsubsection{Proximidade da placa de suporte}

A proximidade da placa de suporte interfere diretamente na leitura de uma descontinuidade pelo ensaio RFT. Os gráficos da Figura 15 ilustra a relevância do bloqueio de sinal do RFT ocasionado pela adição de material (placa de suporte) na leitura de um furo passante. É possível observar que somente após $115 \mathrm{~mm}$ de distanciamento foi possível identificar completamente a leitura do furo no canal diferencial ( $100 \%$ de perda de espessura, $90^{\circ}$ na fase do sinal).
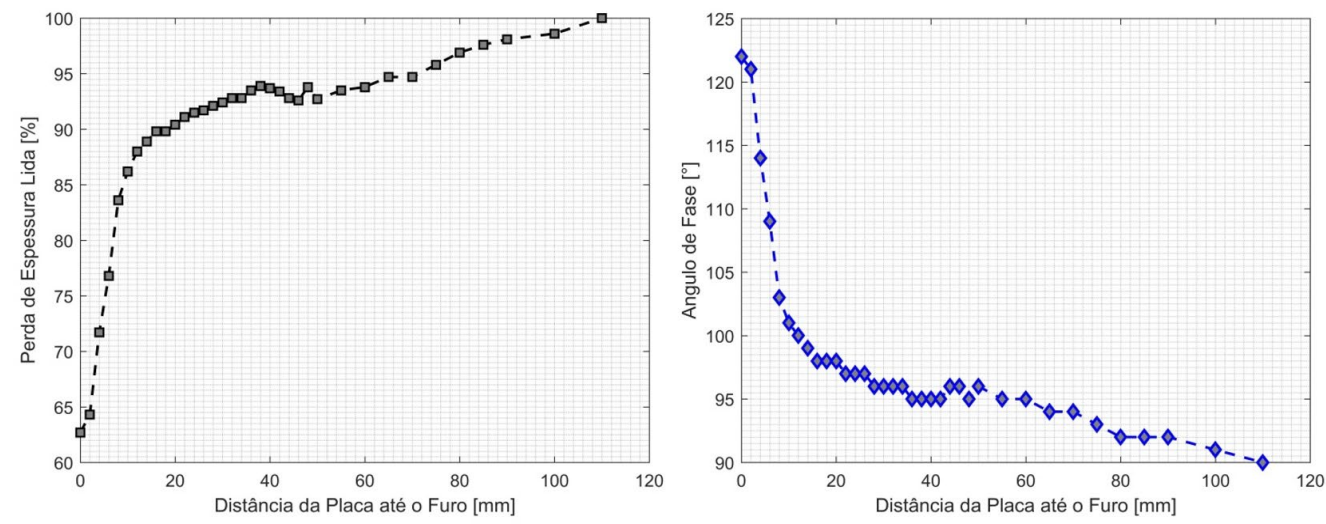

Figura 15. Gráficos de efeito da proximidade da placa de suporte sobre a variação na leitura de perda de espessura e de fase do sinal no ensaio RFT. 


\subsection{Comparativo IRIS-RFT}

$\mathrm{O}$ primeiro ponto de destaque refere-se ao hardware necessário às técnicas. Enquanto a realização do IRIS requer que o tubo analisado esteja completamente preenchido com água (que serve como acoplante para o pulso sônico), o RFT trabalha com o tubo totalmente seco, já que se trata de uma técnica baseada em eletromagnetismo. A ausência de água no ensaio RFT significa um enorme passo no sentido de facilitar a realização da inspeção, dado que manter a coluna de água totalmente livre de bolhas de ar pode ser uma tarefa complicada, além da substancial redução na quantidade de equipamentos necessários (parte do sistema IRIS), a exemplo: bomba e reservatório de água, sonda com espelho e turbina (que possui partes móveis) e sobretudo equipamento de proteção adequado para os operadores. Outra vantagem do RFT sobre o IRIS é a alta velocidade de execução, sendo possível realizar a inspeção integral de tubos de $6 \mathrm{~m}$ de comprimento em menos de quarenta segundos com velocidades típicas de ensaio que giram em torno dos $500 \mathrm{~mm} / \mathrm{s}$ (Birring, 2001 apud Sabino, 2008; Carneval, 2002 apud Sabino, 2008), se contrapondo aos 75 mm/s do IRIS (Al-Qadeeb, 2005; Birring, 2004 apud Sabino, 2008).

A Figura 16 mostra um comparativo ilustrativo entre as técnicas RFT e IRIS. Esse comparativo foi realizado utilizando o tubo padrão desenvolvido para a técnica de RFT. A partir de ensaios pelas duas técnicas nesse tubo, é possível visualizar o strip chart do RFT e o C-SCAN do IRIS para cada descontinuidade no tubo, mostrando a diferença de resultado visual em cada ensaio. Já a Figura 17 mostra as descontinuidades examinadas e uma comparação do plano de voltagem e sinais de lissajous do RFT com a planificação da parede do tubo no IRIS. A Figura 18 mostra um gráfico comparativo das porcentagens de perda da espessura da parede obtidas com IRIS e RFT. Por essas figuras, nota-se que o IRIS é uma técnica mais intuitiva e visual de se trabalhar quando comparada ao RFT. No caso do IRIS o resultado da inspeção é exposto em gradientes de cores com formato bem próximo da descontinuidade, sendo sua geometria exibida em uma vista planifica do tubo. Entretanto, nota-se que apesar do RFT não ser, a priori, uma técnica visualmente intuitiva, seus resultados em perda de espessura se assemelham bastante aos resultados do IRIS. Em termos de descontinuidades pontuais, o RFT se apresenta visualmente fácil de compreender pelo strip chart, o plano de voltagem e o lissajous. O processo de calibração do IRIS é, também, mais simples, sobretudo porque não é necessária a determinação de parâmetros de perda de espessura como referência para o software (a leitura é baseada exclusivamente na avaliação do tempo de viagem do pulso sônico). Por conta desses atributos, o RFT caracteriza-se como uma técnica que apresenta bastante dependência da experiência do operador em identificar e interpretar as particularidades do sinal.

A Figura 19 ilustra graficamente um comparativo entre as perdas de espessuras medidas pelo IRIS e o RFT usando desta vez tubos fornecidos por uma empresa de óleo e gás. Entende-se por essa figura que para descontinuidades de maior tamanho o desempenho do RFT se aproximou mais daquele do IRIS, havendo uma diferença pequena com um erro relativo em torno de $8 \%$ para mais ou para menos (tomando o IRIS como a técnica correta). Entretanto, em alguns casos o RFT apresentou resultados distantes dos que foram reconhecidos pelo IRIS, o que se relaciona à forma geométrica das descontinuidades. O RFT apresentou dificuldades na detecção da perda de espessura do rasgo longitudinal de menor largura, dos pittings em série e pittings radiais. Também não é possível identificar pelo RFT o exato formato da descontinuidade, como foi observado nas leituras dos pittings em série ou dos rasgos longitudinais, conforme a Figura 20. Apesar disso, a técnica RFT foi capaz de reconhecer um pitting isolado que o IRIS não foi capaz de ler devido aos ecos de borda produzidos por essa descontinuidade.

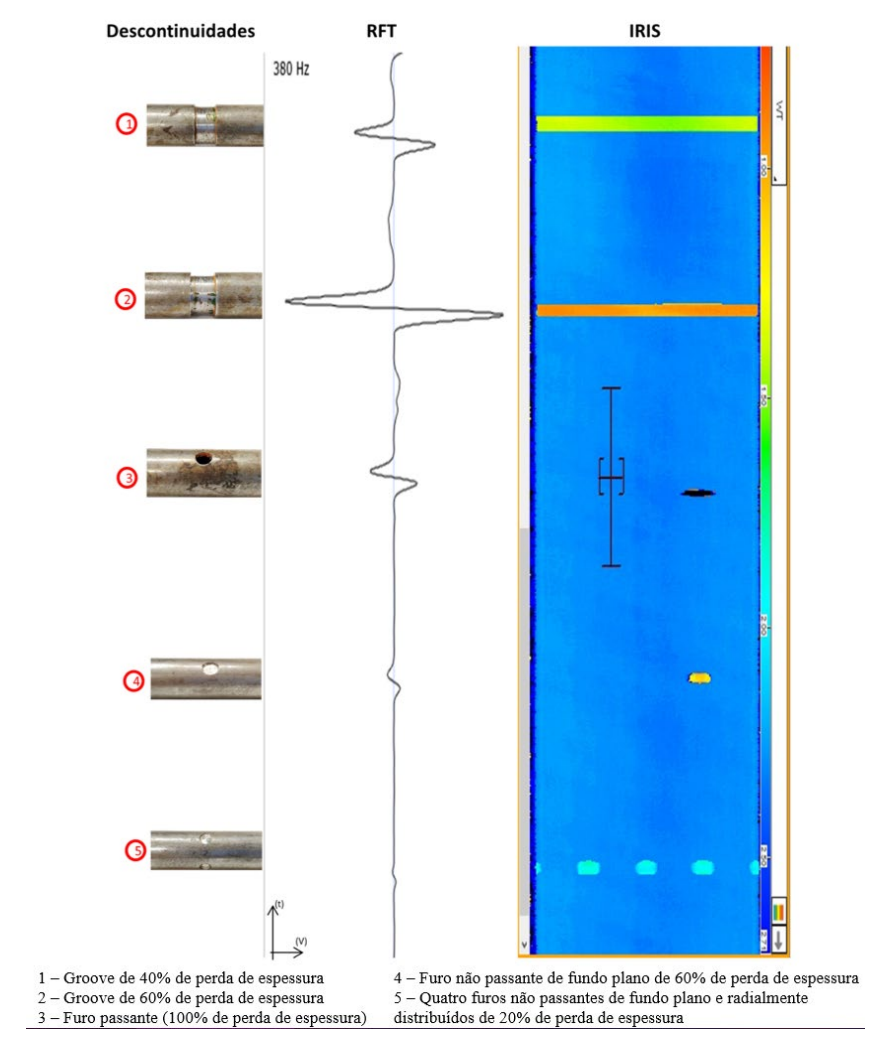

Figura 16. Comparativo visual entre os resultados dos ensaios RFT e IRIS utilizando o tubo padrão. 


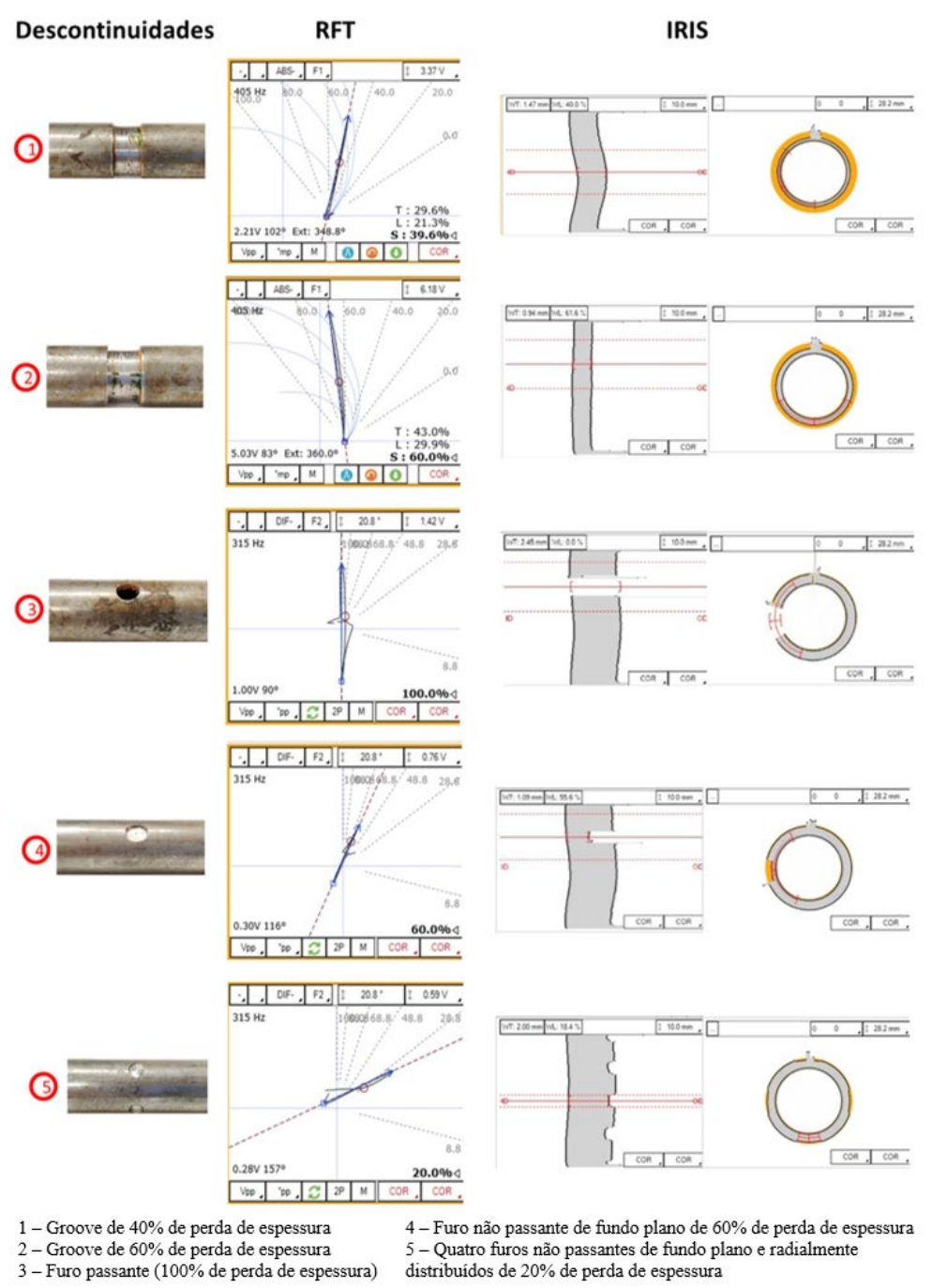

Figura 17. Comparativo visual do plano de voltagem e lissajous do RFT com a planificação do tubo no IRIS utilizando o tubo padrão.

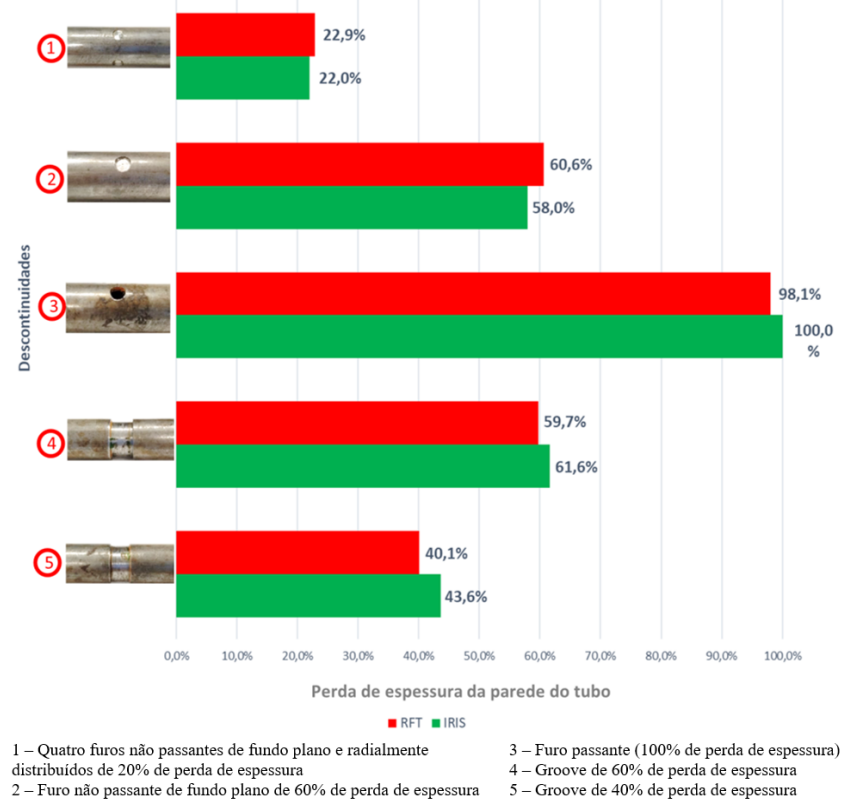

Figura 18. Gráfico comparativo da porcentagem de perda de espessura obtida com IRIS e RFT no tubo. 


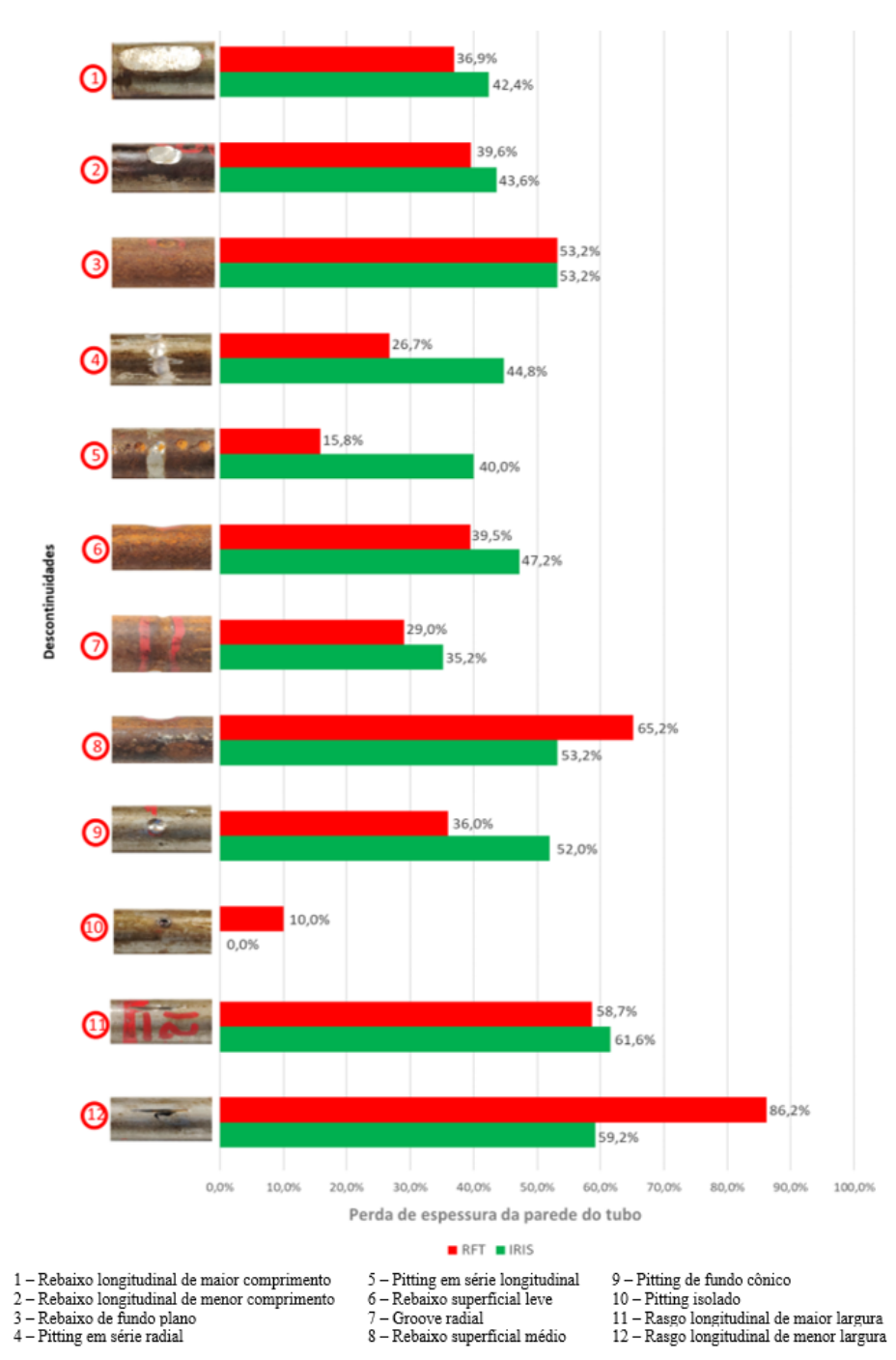

Figura 19. Gráfico comparativo da porcentagem de perda de espessura obtida com IRIS e RFT em tubos fornecidos por uma empresa de óleo e gás.
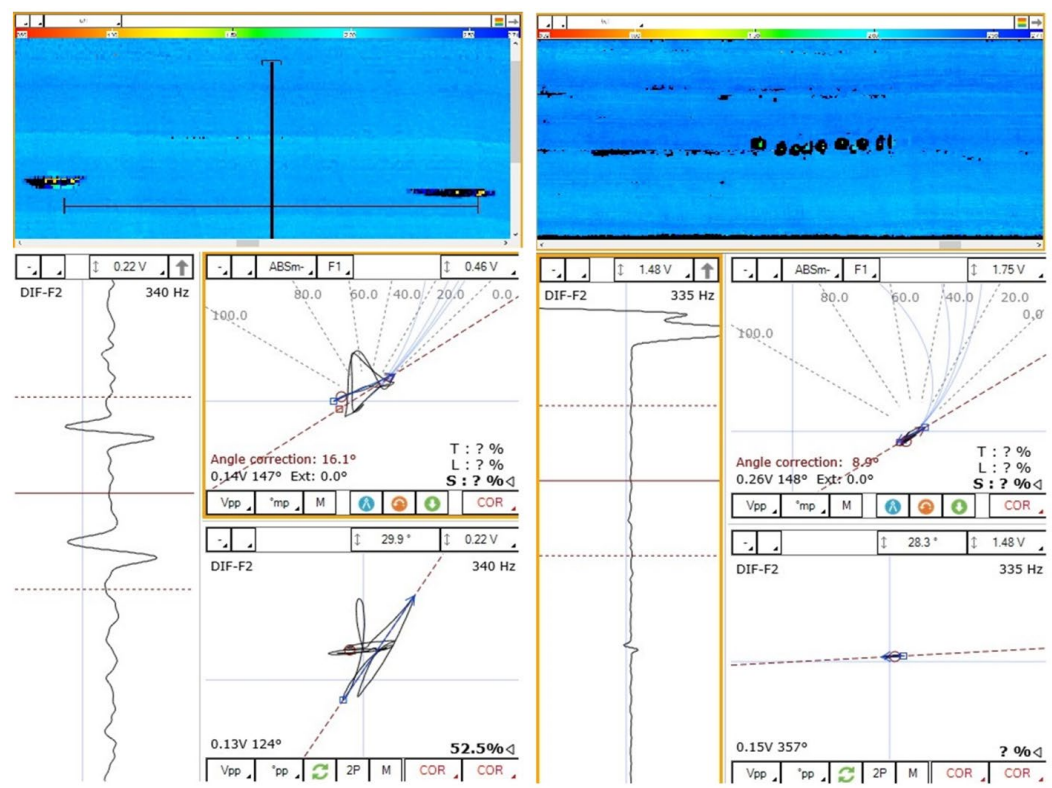

Figura 20. Comparativo visual entre os resultados dos ensaios RFT (abaixo) e IRIS (acima) para descontinuidades do tipo rasgo longitudinal (à esquerda) e pitting (à direita). 


\section{Conclusões}

Este trabalho foi realizado no intuito de melhorar o entendimento do ensaio não-destrutivo RFT e da influência de seus parâmetros de operação, como frequência de excitação, velocidade de tracionamento da sonda e a influência da placa de suporte na leitura e interpretação de seus resultados, bem como avaliar seu desempenho frente ao ensaio não-destrutivo IRIS diante de variados tipos de descontinuidades. Com base nas condições de testes e para os parâmetros utilizados, pode-se concluir que:

- $\quad$ O melhor conjunto de frequências de excitação emitidas pela sonda RFT foi de $400 \mathrm{~Hz}$ para o canal absoluto e $280 \mathrm{~Hz}$ para o diferencial, ainda que essa seja uma configuração exclusiva para cada trocador e que precisa ser determinada no momento do ensaio;

- $\quad$ O cenário ideal para a realização do ensaio RFT é calibrar o sistema a uma dada velocidade de varredura e então reduzir sensivelmente sei nível para a realização dos ensaios em si com o intuito de garantir a amplitude adequada das leituras e uma melhor detecção das descontinuidades;

- A menor distância que uma descontinuidade deve estar da placa do suporte do trocador de calor para que a mesma seja encontrada na leitura do canal diferencial e do canal absoluto do RFT foi de $115 \mathrm{~mm}$, e a utilização do canal MIX fez-se necessária para encontrar descontinuidades próximas à placa de suporte;

- $\quad$ Em termos de execução, o RFT apresentou-se mais rápido e prático por não necessitar de água e pelo equipamento depender de menos acessórios, sendo operar o ensaio em cada tubo de 6 metros em menos de um minuto;

- Em termos de leitura e análise dos resultados, apesar do RFT oferecer maiores dificuldades na interpretação dos dados, foi possível verificar que, para descontinuidades de maiores dimensões, a performance com RFT se assemelha à com o IRIS. Já para descontinuidades menores ocorreu uma maior dificuldade na leitura com o RFT.

Em suma, pode-se dizer que o ensaio RFT é complementar ao IRIS, podendo ser usado para análises rápidas em locais de difícil acesso e onde a quantidade de equipamentos a ser avaliado é um fator relevante. Ou seja, o RFT pode ser utilizado mais como ferramenta de varredura célere de cunho mais geral no equipamento e o IRIS como instrumento de investigação mais minuciosa e local. Isso pode ser uma perspectiva promissora para a avaliação de vida remanescente de trocadores de calor do tipo casco e tubos, sobretudo no que diz respeito à indústria de óleo e gás, na qual as inspeções são bastante dispendiosas e a segurança durante as operações fundamental.

\section{Agradecimentos}

Os autores agradecem à CAPES (código financeiro 001) e ao CNPq (bolsa 315092/2018-1), ao Centro para Pesquisa e Desenvolvimento de Processos de Soldagem (Laprosolda-UFU) e ao Laboratório de Acústica e Vibrações (LAV-UFU) pela infraestrutura utilizada, e em especial à Petrobras-CENPES-ANP pelo apoio laboratorial e financeiro.

\section{Referências}

Al-Qadeeb FE. Tubing inspection using multiple NDT techniques. In: MENDT. 3rd Middle East NDT Conference and Exhibition. Manama. Manama: MENDT; 2005 [acesso em 10 fev. 2020]. Disponível em: https://www.ndt.net/search/docs.php3?showForm=off\&id=3309

American Society for Testing and Materials. E2096/E2096M-16: Standard practice for in situ examination of ferromagnetic heat-exchanger tubes using remote field testing. West Conshohocken: ASTM; 2019.

American Society of Mechanical Engineers. Remote Field Testing (RFT) examination method. New York: ASME; 2019.

Ginzel E. Civa modelling for internal ultrasonic tube testing. Journal of Nondestructive Testing. 2018;2018(4):1-22.

Guérard M, Renaud J, Aubé D, Savard, S. Studying the sensitivity of remote-field testing signals when faced with pulling speed variations. Journal of Nondestructive Testing. 2017;2017(10):1-9.

Huang SE, Wang S. New technologies in electromagnetic non-destructive testing. Singapore: Springer Series in Measurement Science and Technology; 2013. 222 p.

Nogueira R. Inspeções em trocadores de calor. Belo Horizonte: BCend; 2015. [acesso em 03 mar. 2020]. Disponível em: https://bcend.com.br/inspecoes-em-trocadores-de-calor/.

Ornelas R. Entendendo o ensaio de ultrassom IRIS. Belo Horizonte: New Wave NDT; 2017 [acesso em 03 mar. 2020 ]. Disponível em: https://newwavendt.com.br/entendendo-o-ensaio-de-ultrassom-iris/

Ramos JE. Revisão da guia de boas práticas para inspeção de permutadores de calor do tipo casco e tubo. Rio de Janeiro: CENPES; 2015.50 p. 
Sabino RS. Inspeção de feixes tubulares de trocadores de calor [dissertação de mestrado]. Belo Horizonte: Universidade Federal de Minas Gerais; 2008. [acesso em 13 fev. 2020]. Disponível em: https://docplayer.com.br/4799612-Inspecao-de-feixes-tubulares-de-trocadoresde-calor.html

Soares A. Correntes parasitas. São Paulo: ABENDE; 2005. 203 p. 